\title{
A autoformação docente como território de possibilidade: uma reflexão sobre o espaço escolar
}

\author{
La autoformación docente como territorio de posibilidad: una reflexión
} sobre el espacio escolar

The self teacher training as a territory of possibility: a reflection on the school space

\author{
Ma. Tascieli Feltrin ${ }^{1}$ \\ Ma. Natália Lampert Batista ${ }^{2}$ \\ Dra $^{\mathrm{a}}$. Elsbeth Léia Spode Becker ${ }^{3}$
}

\begin{abstract}
Resumo
Refletir o processo dinâmico e inquietador de autotransformar-se pela docência é algo complexo e extremamente necessário à atuação docente em suas diversas práticas, sejam elas coletivas, sociais, ou subjetivas. Desse modo, a proposta deste estudo nasce das inquietações de educadoras sobre suas autoformações em realidades distintas. Assim, no presente relato buscamos refletir sobre os processos de constituição do ser docente, por um viés autobiográfico, com base em experiências vivenciadas em sala de aula. Portanto, em termos gerais, é possível inferir que o processo de (auto) formação de professores somente se concretiza na prática; somente nos tornamos educadores na vivência da sala de aula, na reflexão e na constante transformação frente aos cotidianos que surgem diariamente no território escolar. A partir das considerações aqui tecidas, concluímos que, para tornar-se professor, é necessário vivenciar o espaço escolar, buscando constantemente repensar os desafios enfrentados, aprendendo com as novas situações que surgem e concretizam a prática docente.
\end{abstract}

Palavras-chave: Autobiografia; Reflexão sobre a Prática; Realidade Escolar.

\section{Resumen}

Reflejar el proceso dinámico e inquietante de autotransformarse por la docencia es algo complejo y extremadamente necesario a la actuación docente en sus diversas prácticas, sean estas colectivas, sociales, o subjetivas. De este modo, la propuesta de este estudio nace de las inquietudes de educadoras sobre sus autoformaciones en realidades distintas. Así, en el presente relato buscamos reflexionar sobre los procesos de constitución del ser docente, por un sesgo autobiográfico, con base en experiencias vivenciadas en clase. Por lo tanto, en términos generales, es posible inferir que el proceso de (auto) formación de profesores sólo se concreta en la práctica; Sólo nos hacemos educadores en la vivencia de la clase, en la reflexión y en la constante transformación frente a los cotidianos que surgen diariamente en el territorio escolar. A partir de las consideraciones aquí expuestas, concluimos que para convertirse en profesor es necesario vivenciar el espacio escolar buscando constantemente repensar los desafíos enfrentados, aprendiendo con las nuevas situaciones que surgen y concretan la práctica docente.

Palabras clave: Autobiografía; Reflexión sobre la práctica; Realidad Escolar.

\footnotetext{
${ }^{1}$ Mestra em Educação, UFSM, Santa Maria, RS, Brasil; tascifeltrin@ gmail.com.

${ }^{2}$ Mestra em Geografia, UFSM, Santa Maria, RS, Brasil; natilbatista3@ gmail.com.

${ }^{3}$ Doutora em Agronomia, UNIFRA, Santa Maria, RS, Brasil; elsbeth.geo@gmail.com.
} 


\begin{abstract}
Reflecting the dynamic and disturbing process of (self) transformation through teaching is something complex and extremely necessary for the teaching performance in its various practices, be they collective, social, or subjective. Thus, the proposal of this study is born of educators' concerns about their (self) formations in different realities. In this way, in the present report we seek to reflect on the processes of constitution of the teaching being, by an autobiographical bias, based on experiences lived in the classroom. Therefore, in general terms, it is possible to infer that the process of (self) formation of teachers only materializes in practice; We only become educators in the experience of the classroom, in the reflection and in the constant transformation in front of the daily ones that appear daily in the school territory. Based on these considerations, we conclude that in order to become a teacher it is necessary to experience the school space by constantly seeking to rethink the challenges faced, learning from the new situations that arise and concretizing the teaching practice.
\end{abstract}

Keywords: Autobiography; Reflection on Practice; School Reality.

\title{
1. Introdução
}

A experiência docente, a nosso ver, é o território próprio da formação de professores, pois só ela atua com forças vivas e inquietantes sobre os sujeitos, forças estas que não se encontram plasmadas nos espaços escolares, tampouco nas universidades. A autoformação, aqui, é entendida como uma produção de si próprio, coletiva e subjetiva. A docência, nessa perspectiva, para além de um título é um processo de autotransformação. Não se chega a ser docente sem vivenciar a docência, sem ser atravessado pelos inúmeros conflitos que cerceiam o cotidiano escolar e transformam as práticas e as percepções do espaço-escola.

Essa experiência cotidiana é constituída pelos processos subjetivos de ordens múltiplas, fazendo com que não exista uma receita para se autoformar professor, pois cada realidade age sobre e no docente de maneiras distintas e é interpretada pelos diferentes sujeitos de formas diferenciadas. Os desafios à atuação docente podem surgir, inclusive, da realidade de cada um dos alunos e infelizmente, muitas vezes, os cursos de formação de professores não dão conta de preparar seus egressos para a atuação em realidades que se distanciam dos modelos sobre os quais as teorias em voga têm se sustentado.

Muitas dessas teorias são construídas por pesquisadores que desconhecem a escola real, pautam-se nas escolas e modelos escolares ideais e depois tentam encaixar toda essa complexidade de relações nos seus esquemas e proposições. Esse distanciamento entre as proposições teóricas acerca da escola e o seu cotidiano mascaram as condições das escolas brasileiras, especialmente, das públicas e fazem os alunos de graduação se iludirem, pensando que o problema do espaço escolar são as metodologias de ensino. Enganam-se! A cultura pósmoderna do imediatismo, da fragmentação e da superficialidade e os problemas estruturais presentes no espaço escolar têm contribuído muito mais para a ineficiência do modelo escolar do que a formação e inovação pedagógica dos docentes tão exaltadas como o problema de aprendizagem dos estudantes da educação básica. Talvez a escola não seja simplesmente 
chata! Talvez, o tipo de sociedade em que vivemos não valorize o estudo e a construção de conhecimentos não voltados a uma aplicação imediata, momentânea, passageira! ${ }^{4}$

É natural, sob a perspectiva apresentada anteriormente, que os docentes ao se depararem com realidades diversas e conflitantes com as concepções teóricas estudadas na graduação assumam a responsabilidade sobre o fracasso dos métodos de ensino que não acompanham a pluralidade de inquietações que estão presentes nas situações escolares. A cobrança de si emerge da constatação sobre a distância entre o real e o ideal ${ }^{5}$ e esta cobrança pode tornar a experiência docente muito traumática. A gestão das diversas demandas da profissão requer que o docente não se culpabilize e tampouco se exima de responsabilidades. Este equilíbrio só se encontra na problematização das experiências constituidoras dos processos de autoformação.

A tendência a considerar a autoformação como importante processo constituidor da prática docente é, todavia, bastante recente. Nesse sentido, buscamos refletir sobre os processos de constituição do ser docente, por um viés autobiográfico, com base em experiências vivenciadas em sala de aula. Assim, a proposta deste estudo nasce das inquietações que atravessam três educadoras, em realidades muito distintas, mas com um compromisso social, ético e estético semelhante, o de emancipação dos indivíduos e dos grupos sociais. O desafio maior, encontrado no processo de autoformação pela e na docência, está na promoção de encontro entre as atividades de ensino e a realidade sociocultural dos alunos. Na sequência, busca-se pensar que outros modos de ser e se fazer docente a realidade nos proporcionou e nossas considerações acerca da experiência vivida. Dessa forma, propõese como perspectiva de autoformação não necessariamente uma formação continuada, mas uma formação durante a vida, pela e na prática.

\section{Autotransformar-se educador na e pela prática}

Saímos dos cursos de formação inicial e continuada repletos de certezas traduzidas em metodologias, em teorias educativas, em leituras, enfim, preparados no âmbito do conhecimento, da fluência em conteúdos e em metodologias, o que é um requisito fundamental para avançar na profissão-docente. No entanto, a relação com a docência só inicia, efetivamente, a partir da interação de âmbito sócio-pessoal com os sujeitos que compõem o universo escolar. O constituir-se docente é, assim, um processo que ocorre na

\footnotetext{
${ }^{4}$ As ideias apresentadas corroboram com a opinião do renomado sociólogo Zygmunt Bauman que aponta que a educação vem sendo vitimada pela cultura do imediatismo e da fragmentação conforme o vídeo disponível em: https://www.youtube.com/watch?v=a-aNRT8N90s, acesso em julho de 2017.

${ }^{5}$ Ideal que é aprendido nos processos formadores.
} 
prática mediada por concepções teóricas, metodológicas, éticas e estéticas tecidas desde a formação inicial, mas principalmente na vivência cotidiana do espaço escolar.

É a vivência profissional, a experiência, a interação com os conflitos que possibilitam ao docente encontrar uma ética profissional coerente com as condições de possibilidade de sua atuação. Ou seja, a produção de sentido à docência se dá através das experiênciase é mediatizada pelas especificidades do meio em que se dá. A relação da docência com a pobreza, com a violência, com as novas tecnologias, com o aprisionamento, com a vulnerabilidade social, entre tantos outros fatores, influencia de maneira significativa as possibilidades de autoformação, pois estimula a transformação da formação inicial para melhor interagir com as necessidades que a experiência apresenta.

Os fatores sociais assumem tamanha importância no sentido em que intervêm na dimensão pessoal, da formação da consciência dos docentes. Segundo Pereira (2000), o processo de formação profissional envolve necessariamente a produção de si, isto é, do sujeito-professor. De maneira análoga, Maciel (2003, p.1) defende que a autoformação é também "espaço de investimento do próprio sujeito em si mesmo e na sua formação, a partir do momento em que toma consciência das suas necessidades e dificuldades". Acerca das necessidades e dificuldades da atuação docente, Maciel (2003, p.1) considera-as como "limites situacionais", os quais podem impedir ou impulsionar "o sujeito para a mudança transformando-as em possibilidades de autoformação".

A autoformação é fundamental para que haja, realmente, mudança na prática do professor porque houve uma mudança nele mesmo. Mas esse processo de autoformação precisa estar embasado na consciência que o professor tenha do tipo de dificuldades e necessidades a serem enfrentadas e dos recursos que é capaz de catalisar e mobilizar nele mesmo para que aconteçam tais mudanças. (MACIEL, 2003, p.4).

Também em Freire, na obra Pedagogia da Autonomia (2004), encontramos subsídios para pensar estes processos constitutivos do ser professor. Para o educador (2004, p.75), "ninguém é sujeito da autonomia de ninguém. Por outro lado, ninguém amadurece de repente, aos vinte cinco anos. A gente vai amadurecendo todo dia, ou não. A autonomia, enquanto amadurecimento do ser para si, é processo, é vir a ser". A autoformação, a partir destas considerações, engloba a escolha por uma postura profissional (ativa ou não) diante das situações escolares e, também, das políticas (públicas) educacionais. No contexto das situações atuais que colocam o docente frente a estes "limites situacionais", destacam-se a necessidade de reflexão sobre o papel social do professor, as modificações culturais da pós- 
modernidade e a relação com os novos conhecimentos e habilidades que as tecnologias digitais introduzem no cotidiano escolar. Fazer de tais situações, experiências, é uma escolha do sujeito, que não se relaciona com sua formação acadêmica, mas sim, com a maneira como lida com seus limites e possibilidades. Ou seja, passar pelas situações de possibilidade não configura processo de autoformação, pois submeter-se à experiência é uma escolha pessoal e também coletiva e subjetiva.

A autoformação docente emerge de um campo de inquietações do ser humano incompleto que habita o ser docente. As vivências, as carências, os medos, as certezas e o desejo de ensinar e de aprender constantemente são os mediadores do processo de autotransformação. Ninguém se autoforma ou investe em uma profissão e na busca por melhores habilidades docentes se não acreditar no que faz, se não se apaixonar pelos pequenos resultados, fruto de muita dedicação, de muito estudo, de muito planejamento. A trajetória docente, assim, necessita ser pensada a partir dos momentos pequenos e cotidianos que somados, refletirão na qualidade do ensino-aprendizagem como processo longo e demorado, mas também e principalmente ratificarão o amadurecimento do profissional e a qualificação de sua prática. Portanto, se constituir docente é um processo lento, por vezes doloroso, mas transformador. Ninguém é capaz de deixar de ser professor após se torná-lo efetivamente na e pela prática.

\section{O meio como catalisador de experiências: reflexões autobiográficas}

A investigação das situações catalisadoras de possibilidades e também de limites para a autoformação docente passa pela percepção do "como" professores lidam com essas situações. Nesse sentido, a autobiografia nos serve como ferramenta capaz de exprimir essa relação, pois compreendemos que só há autoformação docente a partir da problematização da trajetória e das condições de atuação pelo próprio professor. Nessa perspectiva, o conceito de formação é afetado pela problematização que a experiência desenvolve sobre a compreensão, especialmente, no que se refere a dar sentido para o saber docente.

Apresentamos, a seguir, os espaços, condições e atravessamentos que constituíram algumas possibilidades de experiênciação docente e que consideramos parte importante no desenvolvimento de nossa autoformação, como também ideia-força por trás da reflexão que aqui apresentamos.

Primeiramente, cabe desenhar brevemente as condições de possibilidade que apresenta uma das escolas a qual se refere o presente relato. Essa escola se encontra localizada na região administrativa Sul de Santa Maria, RS, e, segundo dados do Censo 
Demográfico do Instituto Brasileiro de Geografia e Estatística (IBGE, 2010), mais de 90\% das residências particulares, desta região, possuem uma renda per capta inferior a dois salários mínimos. Sob essa perspectiva, é importante compreender que a experiência docente dar-se-á em condições bastante díspares das idealizadas ou meramente imaginadas durante os processos acadêmicos de formação. É uma escola real como muitas existentes no Brasil. Não é uma escola ideal como muitas apresentadas nas teorias. Por outro lado, é uma escola possível, capaz de transformar vidas: as dos alunos e as dos professores.

Assim, como mencionado, a escola de vivência encontra-se em uma zona de vulnerabilidade social e essa escola muitas vezes é a principal fonte de oportunidade para os estudantes que ali se constituem e tentam aprender. Porém, os desafios para efetivar uma educação de qualidade nesse espaço esbarram em conhecidas mazelas sociais brasileiras. A literatura dedicada à compreensão da relação da extrema pobreza com os baixos índices de sucesso escolar apresenta uma série de medidas metodológicas que poderiam solucionar o problema. Todavia, o problema da pobreza é de cunho social e não pedagógico, sendo que sua resolução depende de uma série de fatores que vão muito além das possibilidades dos professores: soluções políticas e econômicas que afrontam o modelo de país em voga, que destoam com a cultura do lucro a qualquer preço, que não vêm o humano como humano, mais como recurso (recursos humanos). O desafio, nessas realidades, pode ser posto da seguinte forma: como desenvolver as capacidades em condições distantes das ideais ao seu desenvolvimento? Qual metodologia dará conta de ensinar um aluno subnutrido, com frio e desestimulado?

Nesse sentido, o professor, geógrafo e cientista político, Josué de Castro, tem importantes contribuições a fazer. Castro publicou uma série de obras ${ }^{6}$ dedicadas ao mapeamento das regiões mais atingidas pela fome e pela miséria no país em meados do século XX. Com destaque à obra Homens e caranguejos, esta aborda a questão da importância de conhecer o fenômeno da pobreza e suas implicações pelo contato, pela experiência, pela imersão na realidade dos sujeitos em situação de vulnerabilidade. $O$

\footnotetext{
${ }^{6} \mathrm{~A}$ seguir apresentam-se algumas das obras escritas por Josué de Castro: O Problema Fisiológico da Alimentação no Brasil. Recife: Imprensa Industrial, 1932; O Problema da Alimentação no Brasil. Rio de Janeiro: Companhia Editora Nacional, 1933; Condições de Vida das Classes Operárias do Recife. Recife: Departamento de Saúde Pública, 1935; Alimentação e Raça. Rio de Janeiro: Civilização Brasileira, 1935; Documentário do Nordeste. Rio de Janeiro: José Olympio, 1937; A Alimentação Brasileira à Luz da Geografia Humana. Rio de Janeiro: Livraria do Globo, 1937; Fisiologia dos Tabus. Rio de Janeiro: Nestlé, 1939; Geografia Humana. Rio de Janeiro: Livraria do Globo, 1939; Geografia da Fome: A Fome no Brasil. Rio de Janeiro: O Cruzeiro, 1946; e Geopolítica da Fome. Rio de Janeiro: Casa do Estudante do Brasil, 1951.
} 
autor defende, em seus escritos, que nenhuma teoria ou formação acadêmica é capaz de sobrepujar a influência da experiência:

[...] Não foi na Sorbonne nem em qualquer outra universidade sábia que travei conhecimento com o fenômeno da fome. $\mathrm{O}$ fenômeno se revelou espontaneamente a meus olhos nos mangues do Capibaribe, nos bairros miseráveis da cidade do Recife: Afogados, Pina, Santo Amaro, Ilha do Leite [...] Esta é que foi a minha Sorbonne: a lama dos mangues do Recife, fervilhando de caranguejos e povoada de seres humanos feitos de carne de caranguejo, pensando e sentindo como caranguejo. Seres anfíbios - habitantes da terra e da água, meio homens e meio bichos. Alimentados na infância com caldo de caranguejo: este leite de lama. Seres humanos que faziam assim irmãos de leite dos caranguejos. Que aprendiam a engatinhar e a andar com os caranguejos da lama, de se terem enlambuzado com o caldo grosso da lama dos mangues e de se terem impregnado do seu cheiro de terra podre e de maresia, nunca mais se podiam libertar desta crosta de lama que os tornava tão parecidos com os caranguejos, seus irmãos, com suas duras carapaças também enlambuzadas de lama. (CASTRO, 1967, p. 12-13).

Nesse sentido, de forma análoga ao pensamento de Castro (1967), cabe perceber que a atuação docente em realidades atravessadas por precárias condições de subsistência como os mangues ou as periferias só pode ser avaliada e orientada por suas próprias condições e possibilidades. A autoformação docente, assim, é resultado da experimentação dessa realidade, da devida investigação de suas limitações (tráfico de entorpecentes, fome, miséria, escassez de recursos educacionais, entre outros) e de suas possibilidades (empoderamento da comunidade, ampliação dos horizontes, promoção da autonomia, entre outros).

Partindo dessa perspectiva, pensar o ensino de língua portuguesa ou de geografia não se pauta apenas no conteúdo programático e nos currículos vigentes. Inúmeras situações extracurriculares emergem no cotidiano escolar e não podem ser negligenciadas: alunos com frio e/ou com fome e contextos de indisciplina, violência e criminalidade, machismo e homofobia, preconceitos múltiplos acabam emergindo como um desafio aos docentes. Desafio esse que muitas vezes não foi abordado em sua formação inicial. Logo, o professor necessita aprender com essas situações e se transformar para conciliar os conflitos do território de vivência dos estudantes com a sua prática e os objetivos do ensino.

A realidade escolar distante das teorias, muitas vezes, idealizadas nos cursos de formações de professores, em um primeiro contato, pode refletir na autopunição do professor pelos aparentes fracassos nas metodologias de ensino. Questões como "O que estou fazendo aqui?", "Onde estou errando?" e "Será que tudo que aprendi estava errado?" começam a ecoar nos pensamentos sobre as constantes propostas de ensino que não surtem o efeito esperado. Todavia, com a reflexão sobre o processo de ensino, com a compreensão da realidade 
vivenciada e, muitas vezes, com a colaboração de docentes mais experientes as questões começam a se transformar em "Como posso melhorar isso?", "Que outras formas posso fazer meus alunos compreenderem o que estou tentando ensinar?”. Esse importante processo é aonde de fato nos tornamos professores. É nesta busca por compreender a prática que nos profissionalizamos, nos adaptamos e construímos um diálogo mais efetivo com os estudantes.

Por outro lado, em experiências tecidas em escolas de Classe Média e Alta, na região Central de Santa Maria, RS, os desafios não são menos complexos. Apesar de apresentarem, em geral, as condições consideradas por muitos adequadas para o estudo, a sala de aula ainda é marcada por traços culturais excludentes, fragmentados e que ultrapassam o desafio meramente como metodologia didática ou domínio teórico de determinados conteúdos técnicos e científicos. A fluidez, a superficialidade das relações à supervalorização da avaliação (entendida aqui meramente como conceito quantitativo) em detrimento do conhecimento mutila o processo de ensino e de aprendizagem e se tornam um imenso desafio ao jovem professor, exigindo se autotransformar para dar conta das especificidades dos contextos emergentes.

Da mesma maneira que a desmotivação pelo estudo - marcada em frases como "Professora, eu não preciso estudar! Meu pai tem a $4^{\mathrm{a}}$ série, arruma ar condicionado e ganha muito melhor que a senhora..." - o entendimento que a escola deve meramente preparar para concursos como vestibulares e Exame Nacional do Ensino Médio (ENEM) - como observados em afirmações como "Para que estudar isso se não cai no ENEM" - são limitantes a uma prática voltada à formação de pessoas, à construção de conhecimentos críticos e humanizadora. Ambas as visões pautadas meramente na aplicabilidade do saber, na fragmentação e no tecnicismo do que se sabe, impossibilitam a real construção de conhecimentos e a formação de indivíduos críticos, atuantes e que sejam capazes de se indignar com as misérias humanas, com a corrupção, com a seletividade jurídica existente em algumas esferas da realidade em que vivenciamos, com a exclusão social, com a degradação do meio ambiente, com a desvalorização da vida...

Esses dois contextos extremamente diferentes e muitas vezes distantes das teorias exclusivamente didáticas estudadas por muitos pesquisadores renomados geram apreensão e imensas incertezas no processo de constituição docente. Como atuar em meios tão distintos com uma formação inicial única? Somos realmente docentes após a formatura? É justamente aqui que defendemos que a formação docente somente pode ocorrer na e pela prática em um constante processo de autotransformação, de reflexão e de mudança. 
Programas de iniciação à docência são muito válidos para familiarizar o futuro docente com o território escolar, porém não apresentam a realidade como um todo. Uma vez que é muito diferente estar na sala de aula com um grupo de colegas e orientado por um educador experiente e o momento em que nos vemos sozinhos frente acerca de 30 alunos, necessitando mediar conflitos, ministrar aulas, trabalhar com as diferenças intrínsecas à sala de aula e deparando-nos com situações novas a cada instante.

Assim, a realidade docente acaba perpassando pela compreensão de que muitos conflitos extremos típicos de uma sociedade pós-moderna recaem sobre o cotidiano da sala de aula, bem como entraves burocráticos associados ao modelo de educação adotado no Brasil limitam a prática docente e fazem identificar lacunas que muitas vezes na formação inicial passam despercebidas. Os maiores desafios na profissionalização docente, no espaço escolar, não estão necessariamente pautados em domínio técnico dos conceitos teóricos e metodológicos da área de ensino, mas sim ao processo de constante (re)adaptação ao meio no qual se ensina e se aprende a ser docente.

A constante mudança do professor como profissional é evidenciada por Midlej e Pereira (2016) ao discutirem trajetórias profissionais como destacam:

A trajetória docente, a manifestar-se em constante reorganização - como fluxos existenciais - demonstra a potencialização do sujeito em relação a si próprio (MIDLEJ, 2014). No discurso do professor, o ambiente vivo das experiências didáticas remete a uma força provocativa de rupturas e rearranjos de possibilidades "[...] de acolhimento dos múltiplos que vivem em nós [...]" (MIDLEJ, 2014, p. 320).

Por outro lado, há muitos anos, em nosso país circulam cartilhas, manuais docentes de como ensinar e obter de seus alunos os melhores resultados. Tais materiais muito em voga ainda na atualidade trazem sequências didáticas, planos de aulas, ditam posturas, teorias da aprendizagem e constroem no imaginário social uma atuação docente pronta. Faz parte desse imaginário o mito que o professor, ao concluir o curso de graduação ou se apropriar de um desses manuais, estará apto a enfrentar qualquer realidade.

“Toda a escola é igual”, dizem eles. "Aluno indisciplinado não tem professor com domínio de turma!". "Você precisa se dedicar para encantar os seus alunos... Com poucos minutos a mais de planejamento e metodologias inovadoras todos aprenderão [igual]". "Você precisa ver cada um de seus alunos", mas deve seguir as receitas ditadas pelos teóricos que discutem o ensino seja de língua portuguesa seja de geografia. Nesse sentido, a adoção de um mesmo livro didático para realidades diferentesou a imposição de certos ritos escolares a todas as escolas colaboram com a construção de uma realidade abstrata, idealizada, comum a 
todos. Mas será que todas as escolas têm as mesmas necessidades? E se seguirmos as cartilhas rigorosamente e ainda assim nossos alunos não evoluírem, eu não serei um "bom” professor? Será que as metodologias de ensino são adaptáveis a todas as salas de aula de um país tão grande como o Brasil e a todas as especificidades de todos os alunos?

Por isso, para nos tornarmos "bons" professores, ou seja, professores satisfeitos com suas práticas e que colaboram com a construção do conhecimento dos estudantes, necessitamos desconstruir os estereótipos do "ser professor" que nos prendem a resultados meramente quantitativos muitas vezes expressos por notas vermelhas ou azuis nos boletins escolares. A melhor aula é aquela que faz o estudante pensar sobre o mundo e compreender o seu papel enquanto cidadão e não aquela que somente dá conta do conteúdo programático ou que conduz a aprovações para o Ensino Superior. O melhor professor é aquele que vê o seu aluno e não aquele que meramente o enxerga.

Nesse sentido, o pensamento do educador Paulo Freire tem algo importante a contribuir com a autoformação docente, pois oferece subsídios para que se pense as práticas educativas e a relação professor-aluno de maneira dialógica e reflexiva. Não são metas, nem orientações a nível nacional que podem ser a "melhor" opção para nortear as práticas, mas sim as experiências que apenas a vivência com cada aluno traz ao professor. Para além das questões pedagógicas, o professor inserido em uma realidade como as descritas, necessita abordar essas questões em uma perspectiva crítica, para que seus alunos desenvolvam um olhar consciente sobre sua realidade. Faz parte do "currículo" único e necessário dessas realidades desvelar novas oportunidades de conceber o mundo, menos sofrido e menos violento, mais justo.

Não há conscientização se, de sua prática não resulta a ação consciente dos oprimidos, como classe explorada, na luta por sua libertação. Por outro lado ninguém conscientiza ninguém. $\mathrm{O}$ educador e o povo se conscientizam através do movimento dialético entre a reflexão crítica sobre a ação anterior e a subsequente no processo de luta. (FREIRE, 1982, p 109-110).

A compreensão dessa realidade chega a partir de um pensar constante e sistematizado sobre o que se está ensinando e o que se está aprendendo, sobre o como se está ensinando e como se está aprendendo, para quem se ensina e como se ensina e só é possível quando se efetiva um elo entre o professor e os alunos, quando se pensa sobre a própria autoformação/constituição docente. Ao chegar ao final do primeiro ano de docência e ouvir dos estudantes "Eu gostaria que você fosse minha professora novamente no próximo ano" ou "Eu consegui ver coisas diferentes a partir do que a senhora falou para nós", mesmo 
consciente de que ainda temos muito a melhorar, é uma prova de que bons resultados estão sendo construídos e que os estudantes têm efetivamente inspirado práticas que estão contribuindo com sua vivência de algum modo e que outrora estava pautada apenas na "transmissão" de conteúdos técnicos pautados em "teorias bonitas".

Com base nas experiências vividas, percebemos que o tornar-se professor é muito mais complexo que cursar uma licenciatura e ser habilitado por um diploma. Tornar-se professor é compreender o seu papel social na vida de cada aluno que passa pelo seu caminho, sabendo que o professor não é um "salvador", não tem a obrigação de resolver os problemas estruturais existentes na escola pública brasileira ou o pensamento mercadológico de escolas mais voltadas ao modelo de "qualidade de ensino" em voga, bem como que a eficácia das metodologias de ensino não depende apenas de sua qualidade técnica ou de sua formação inicial, mas do contexto que colabora ou dificulta determinadas práticas pedagógicas.

A autoformação é, assim, antes de tudo uma automudança, consciente, na maneira de viver o território da escola e de tomar decisões com as pessoas que nele convivem, tornando possível a educação vivenciada por todos e efetivada pela automediação. Mészáros (2002) defende que a automediação do processo educativo conduziria a uma vida determinada pelas necessidades humanas efetivas e não pelas necessidades fetichizadas e artificiais criadas no âmbito do capital, cada vez mais dominante no século XX e XXI.

Ensinar na complexidade das relações do século XXI é ter consciência de que é preciso dedicar-se ao máximo pelo ensino de qualidade, mas ao mesmo tempo ter claro que nem toda a aula será magnífica e nem todo o aluno estará disposto a viajar pelo mundo do conhecimento como pregam muitas teorias idealizadas que estudamos e tomamos como verdadeiras antes de nos tornarmos professores. Contudo, ainda há esperança! É possível ensinar! É possível aprender! É possível trocar conhecimentos e construir pequenas e sólidas bases linguísticas ou geográficas que auxiliarão nossos alunos a serem melhores e mais curiosos do que quando chegaram a nossa sala de aula pela primeira vez.

Há uma tendência histórica a se reduzir o ensino de qualquer área de conhecimento à transmissão de conceitos e normas estruturais no âmbito do capital, para servir à reprodução, cada vez mais eficaz, do sistema econômico, como abordado por Mészáros (2002). Nas escolas isso se reflete de maneira que as possibilidades de atuação tornam-se cada vez mais engessadas para os profissionais e o conhecimento movimentado nessas situações é cada vez mais abstrato aos alunos. Nas realidades específicas em que atuamos, essa dinâmica é bastante visível. O movimento fundamental para fazer-se docente, sem recair na alienação dos alunos, organiza-se em duas atividades muito simples: observar e 
refletir. Assim, antes de planejar quaisquer atividades, cabe ao professor observar como os alunos organizam suas práticas comunicacionais e quais elementos do seu cotidiano possuem relevância para a temática, podendo ser utilizados como possibilidade de troca entre os universos da disciplina e dos alunos.

Concentrar seus esforços na reflexão acerca das singularidades próprias da organização de situações educativas que se orientem pela aproximação entre o ensino de conteúdos e a realidade dos alunos identificados com os modos de vida periféricos, pois cada situação educativa é única e o conhecimento acadêmico nem sempre dá conta das exigências do cotidiano escolar. São brigas familiares, dificuldades econômicas, déficits de aprendizagem. O que faz a diferença são os momentos dedicados a conhecer a natureza desses problemas, a criatividade na resolução de conflitos e a resiliência de a cada dia prosseguir, encarando cada experiência educativa como única. Não que a abordagem dos conteúdos não seja o foco do ensino, mas há situações que não podem ser negligenciadas. A intencionalidade docente é sempre educativa independente da situação, o que varia são as ferramentas a que se recorre.

\section{Conclusão}

O processo de se constituir docente em realidades diferentes das ideais sobre as quais são formadas expectativas durante os processos de formação oficiais requer cuidado para que não se culpe o professor, nem aos alunos. Muitas das dificuldades enfrentadas no espaço escolar são sociais, estruturais, geográficas. Assim, é preciso conhecer as peculiaridades de cada território escolar e saber que a função docente é antes de tudo mediar os processos educativos independentes de quais sejam as condições e situações que se apresentem, respeitando sempre as possibilidades de seus alunos, as suas e as da escola em que atua.

Portanto, em termos gerais, é possível inferir que o processo de autoformação de professores somente se concretiza na prática; somente nos tornamos educadores na vivência da sala de aula, na reflexão e na constante transformação frente aos cotidianos que surgem diariamente no território escolar. A partir das considerações aqui tecidas, concluímos que, para tornar-se professor, é necessário vivenciar o espaço escolar, buscando constantemente repensar os desafios enfrentados, aprendendo com as novas situações que surgem e concretizam a prática docente. 


\section{Referências}

CASTRO, J. de. Homens e caranguejos. São Paulo: Brasiliense, 1967.

FREIRE, P. Pedagogia da Esperança: um reencontro com a pedagogia do oprimido. Rio de Janeiro: Paz e Terra, 1992.

Terra, 2004.

Pedagogia da Autonomia: Saberes necessários à prática educativa. Brasil: Paz e

MACIEL, M. D. Autoformação docente: limites e possibilidades. In: Encontro Nacional de Pesquisa em Educação em Ciências, 4., 2003, Recife, Anais... 2003, Recife: SBPC, 2003. p. 1 $-5$.

MÉSZÁROS, I. Para além do capital: rumo a uma nova teoria da transição. São Paulo: Bom tempo, 2002.

MIDLEJ, J. A; PEREIRA, M. V. As Histórias de vida como tramas de fios na composição da professoralidade. Revista Brasileira de Pesquisa (Auto)Biográfica, Salvador, v. 1, n. 3, p. 551-563, set./dez., 2016.

PEREIRA, M. V. Subjetividade e memória: algumas considerações sobre a formação e autoformação. Ijuí: UNIJUÍ, 2000. 